\title{
Communication in intensive care units and cardiac wards - A literature review and personal experiences
}

\author{
Samra Mangafic ${ }^{1}$, Birger Axelsson², Martin J. Holzmann ${ }^{3,4}$, Mikael Arbeus ${ }^{2}$, Christian Bjurman*5 \\ ${ }^{1}$ Department of Emergency Medicine, Halland's Hospital, Varberg, Sweden \\ ${ }^{2}$ Department of Cardiothoracic and Vascular Surgery, Faculty of Medicine and Health, Örebro University, Örebro, Sweden \\ ${ }^{3}$ Department of Internal Medicine, Solna, Karolinska Institutet, Stockholm, Sweden \\ ${ }^{4}$ Functional Area of Emergency Medicine, Karolinska University Hospital, Huddinge, Stockholm, Sweden \\ ${ }^{5}$ Department of Medicine, Halland's Hospital, Varberg, Sweden
}

Received: November 14, 2018

DOI: $10.5430 /$ jha.v8n1p1
Accepted: November 25, $2018 \quad$ Online Published: November 29, 2018

URL: https://doi.org/10.5430/jha.v8n1p1

\begin{abstract}
Background: Physicians are regularly confronted with a wide range of settings requiring good communication skills. Deficient communication is the main reason for patient complaints.

Methods: A literature review and personal experiences of communication techniques used by physicians in intensive care units and cardiac wards.

Results: Good communication can increase medical adherence and motivate patients to life-style changes and therefore improve outcomes, resolve or prevent conflicts, increase patients' satisfaction with offered health care, decrease anxiety and depressive symptoms, instill hope and also make hospital staff feel better.

Conclusions: In this article, different models aiming at achieving optimal results in diverse communication situations are described. Healthcare leaders and medical educators should encourage physicians to use the communication techniques presented in this review to optimize the interaction with patients, relatives and colleagues.
\end{abstract}

Key Words: Communication models, Informing patients, Motivational interviewing, Master suppression techniques

\section{INTRODUCTION}

Good communication can increase medical adherence, ${ }^{[1]}$ and therefore improve outcomes, resolve or prevent conflicts, ${ }^{[2]}$ increase patients satisfaction with offered health care, ${ }^{[3-5]}$ decrease anxiety and depressive symptoms, instill hope and also make hospital staff feel better ${ }^{[6]}$ Deficient communication is the main reason for patient complaints. ${ }^{[7]}$

In Table 1 we present a case-scenario with a patient with a severe pulmonary infection where we decided on "Do not attempt cardiopulmonary resuscitation" (DNACPR) and to abstain from intensive care.
The main objective with this review is to present concise and directly applicable advice regarding communication in intensive care units and cardiac wards. However, the ideas may also be applicable to other types of wards.

\section{MeTHODS}

First, the authors identified, from their work as hospital physicians, relevant and often challenging, communication situations (see Table 2) involving colleagues, critically ill and/or cardiac patients.

A literature review, using PubMed and Google, was then

\footnotetext{
*Correspondence: Christian Bjurman; Email: christian.bjurman@ @regionhalland.se; Address: Halland’s Hospital Varberg, Träslövsvägen 68, 43237 Varberg, Sweden. 
conducted to find concrete advice regarding how to handle and master suppression techniques. Suggested wordings, to the above communication situations. Search words included, be used in each specific setting (see paragraph headings), but were not limited to, patient-centered communication, re- that we have found useful in our clinical work are shown in suscitation, end-of-life care, DNACPR-decisions, feedback quotations marks (“") throughout the manuscript.

Table 1. Case-scenario regarding a critically ill patient on the emergency ward

\begin{tabular}{ll}
\hline Case-scenario & \\
\hline Background & $\begin{array}{l}\text { } 9 \text { years old male with chronic obstructive pulmonary disease and disseminated malignant melanoma. } \\
\text { Oxygen saturation } 69 \% \text {. Temperature } 40.1^{\circ} \mathrm{C} \text {. Cold extremities. Blood pressure } 85 / 45 . \text { Pulmonary } \\
\text { auscultation: Bilateral rales. }\end{array}$ \\
Recommendation & $\begin{array}{l}\text { Standard care. DNACPR. Abstain from intensive care. } \\
\text { "You have a severe infection in the lungs. We will transfer you to the infection ward for further care. Due } \\
\text { to your past medical history and current condition we think that you would not survive a cardiorespiratory } \\
\text { The patient was told }\end{array}$ \\
$\begin{array}{l}\text { standstill. We will, therefore, not attempt resuscitation in the event of cardiorespiratory standstill." } \\
\text { "Your father has a severe infection in the lungs. We will transfer him to our infection ward for further care. } \\
\text { Due to his past medical history and current condition we think that he would not benefit from intensive } \\
\text { care and would not survive a cardiorespiratory standstill. Therefore, we have decided not to attempt } \\
\text { resuscitation in the event of cardiorespiratory standstill and will not transfer him to our intensive care unit } \\
\text { in case of deterioration." }\end{array}$ \\
\hline
\end{tabular}

Table 2. Relevant communication situations identified in every-day hospital care

\begin{tabular}{l} 
Relevant communication situations \\
\hline Exchange of information during rounding on the ward \\
Information about newly diagnosed cancer \\
Informing a patient about end-of-life care \\
Information about resuscitation decisions \\
Motivation for life-style changes \\
Telling patients that they will not get what they want \\
Informing a relative of the death of a loved one \\
Information about discontinuation of life sustaining treatments \\
Dialogues about organ donation \\
Communication by the emergency team in an emergency situation \\
Giving report about a patient to a colleague \\
Constructive feedback \\
Master suppression techniques
\end{tabular}

\section{Communication situations}

\subsection{General principles}

Generally, use clear and simple language and avoid medical terminology when speaking with patients and their next of kin. Pictures (for instance x-ray images), illustrations or movies (ultrasound images etc.) may explain complicated phenomena. Metaphors sometimes clarify points. Consider the use of humor. ${ }^{[8]}$ Patient-centered communication (see Table 3) may help understand the patient's perspective of his/her illness and contribute to shared decision making. ${ }^{[9]}$
Table 3. Components of patient-centered communication ${ }^{[9]}$

\begin{tabular}{l}
\hline Open-ended questions \\
\hline Active listening \\
Explore the patient's feelings, concerns, expectations and experiences \\
Support, name feelings and show understanding and respect \\
Explore patient's prior knowledge and preferences for depth of information \\
Shared decision-making \\
Avoid interruptions \\
\hline
\end{tabular}

An important requisite to be able to communicate well is also the awareness of different psychological phases of a crisis (see Table 4). ${ }^{[10,11]}$

Physicians should also be aware of cultural aspects of communication, as different approaches may be appropriate in different regions of the world. However, do not assume that a certain behavior is appropriate solely based on skin color, physical appearance, dress or participation in a specific ethnic group. ${ }^{[12]}$ In cross-cultural communication, it may be even more important to explore the patient's view of the disease, by asking questions like: "What do you think your sickness does to you? How does it work?" and "What have you done about your illness?" or "What type of treatment do you think you need?"[13]

\subsection{Non-verbal communication}

High patient satisfaction is related to less time spent by the physician reading medical charts with the patient present, and more forward lean, use of nodding, gestures, gazing, smiling, eye contact, expressive tone of voice and closer interpersonal

ISSN 1927-6990 E-ISSN 1927-7008 
distance. ${ }^{[14-16]}$ Touch may also be used to emphasize pieces of information.

\subsection{Communication with patients}

\subsubsection{How to inform during ward rounds?}

Ideally, wait to speak with the patient until all pertinent test results have arrived, so that you can present a carefully prepared and balanced care plan. Start by introducing yourself and other colleagues present, like nurses and medical students, and ask what the patient has been told so far. Students should preferably be presented as "future colleagues". Followed by: "I have read your medical record, but could you please tell me with your own words why you were admitted?" Before revealing a new diagnosis, the patient's prior knowledge and preferences for the depth of information desired should ideally be assessed. ${ }^{[9]}$ Present important test results and tell the patient if a final diagnosis is made or if additional tests are necessary for clarification. To understand the patient's perspective, the physician should explore the patient's feelings, ideas, concerns, and experiences regarding the impact of the illness, as well as the patient's expectations from the physician. ${ }^{[9]}$ Do not forget to discuss preliminary care plans and discharge plans. ${ }^{[17]}$ After disclosing the diagnosis, physicians should invite patients to consider the pros and cons of different treatment options, including no treatment, ${ }^{[9]}$ thus respecting the patient's autonomy. Always give adequate advice. For instance, do not recommend a poor person to take up an activity he or she may not have the funds for. In case of suspicion of malignancy, tell the patient for instance: "We have seen changes on your x-ray that need further clarification. Do you want us to continue with further work-up, like a computed tomography, to be able to exclude a serious condition?"

Table 4. Psychological phases of a crisis ${ }^{[10,11]}$

\begin{tabular}{ll}
\hline Phase & \\
\hline Shock phase & May include denial, emotional shutdown or shouting. \\
Reaction phase & $\begin{array}{l}\text { May include anxiety, self-accusations and the need to blame someone else. } \\
\text { May cause problems with memory and concentration, irritability and withdrawal from social relationships. } \\
\text { Processing phase }\end{array}$ \\
$\begin{array}{l}\text { One tries to understand what has happened and what it means. } \\
\text { Reorientation phase }\end{array}$ & What has occurred now becomes part of everyday life. \\
\hline
\end{tabular}

\subsubsection{How to inform a patient about a cancer diagnosis?}

Before talking to the patient, memorize important information leading up to the diagnosis. ${ }^{[18]}$ If possible, switch off your phone or give it to a colleague. Beforehand arrange for a nurse to take over after 20-30 minutes, when the time of the consultation has run out. ${ }^{[18]}$ Summon the patient to an environment of privacy such as physician's office where the patient can express his/her feelings freely. ${ }^{[19,20]}$ Preferably, the patient should bring a relative. ${ }^{[18]}$ We therefore recommend that the conversation be postponed until that can be arranged. Initiate the discussion with a short introduction: "You have gone through a thorough work-up with x-rays and blood-sampling, and we now know what disease you have." ${ }^{[18]}$ From the initial interview, physicians should try to tell the truth and give as much information as they have available. ${ }^{[20]}$ Therefore, initially use suspicion or possibility of cancer and later, after a definite diagnosis is made, give accurate information. ${ }^{[20]}$ Do not use paraphrasing, thus use the word cancer, not cell changes, ${ }^{[18]}$ and do not explain all details on one occasion. It is usually better to have several interviews with patients to discuss the diagnosis. ${ }^{[20]}$ Avoid overloading the patient with too much information and tech- nical explanations. ${ }^{[20]}$ Avoid detailed prognostic information based on study data. Be less specific: "Honestly, I don't know when you will die. Predictions about survival often prove wrong." Or, if the patient asks if he/she will die, you may say, if applicable: "I think it can be within weeks to months rather than years" or "I do not believe that you have years left to live". ${ }^{[18]}$ Strong emotions are common, so consider holding the patient's hand, putting a hand on the patients shoulder, or moving the chair closer. ${ }^{[18]}$ Always offer hope and reassurance. ${ }^{[20]}$ The physician should, after the diagnosis has been explained, tell the patient that he/she is always ready to support the patient psychologically: "You are not alone, we will help you."[18]

\subsubsection{How to inform a patient about end-of-life care?}

Disease is not always curable. The main objective of care may be changed from life prolongation to palliation. Information about the transition to palliative care leads to empowerment, participation and a more adequate care. ${ }^{[21]} \mathrm{A}$ conversation led by the physician responsible for treatment, should include ${ }^{[22]}$ a discussion with the patient regarding what he/she wants to discuss, followed by what the physician wants to talk about: "I want to discuss your stage of disease 
and how we should plan your further care." Inform that the patient has reached an end-of-life phase: "Your disease is no longer curable, but we will offer you best possible symptom relief and other support measures." Inform the patient that he/she will now not benefit from life-prolonging therapies and that further care is aimed at improving quality of life and obtaining symptom relief. Also inquire into what the patient thinks about his/her disease and wishes, regarding home/hospital care and other assistance, in case of deterioration.

\subsubsection{How to inform about resuscitation-decisions?}

DNACPR-decisions involve both ethical concerns and legal challenges. ${ }^{[23]}$ Appropriate reasons for DNACPRdecisions $^{[24]}$ are that the patient does not want CPR or that the responsible physician's medical judgment is that CPR will not lead to restoration of spontaneous circulation or that CPR may restore spontaneous circulation but would not benefit the patient. Swedish physicians are not obliged to routinely discuss CPR in case of a low probability of cardiopulmonary standstill. ${ }^{[25]}$ When successful CPR is deemed highly unlikely, physicians are not obliged to follow wishes to perform CPR from patients or their next of kin. ${ }^{[25]}$ It is worth mentioning that it may be extremely difficult to assess prognosis, quality of life and stage of disease. For instance, certain cancer patients and persons with mild dementia may live long with a good quality of life.

Initiate the CPR-discussion by talking about the patient's current life situation, diagnosis and prognosis, followed by asking the patient about his/her attitude towards CPR. ${ }^{[26]}$ Only 5\% with a chronic illness knowing that their life expectancy is less than one year want CPR. [27]
Also inform about the usually poor outcomes of CPR in order to allow for more informed decision-making. ${ }^{[28]}$ For instance, the overall rate of survival to discharge is only $17 \%$ after in-hospital cardiac arrest and, among survivors, clinically significant neurologic disability occurs in $28 \%$. ${ }^{\text {[29] }}$ When informing of a DNACPR decision state clearly that "resuscitation will not be attempted in the event of cardiorespiratory standstill". [30] In Sweden, acquiring DNR agreement does not require signing of a specific form; the physician just writes the decision in the medical chart and informs the patient. We are used to explain intubation as a procedure where a machine takes over the breathing for the patient through a special tube that is placed in the windpipe, until the lungs have regained their function. Life support is a wider term used for measures aiming at supporting life after the failure of one or more vital organs, like the heart, lungs or kidneys. We use to tell the patient that a machine or certain drugs will be used temporary to support the failing organ, until it has recovered.

\subsubsection{How to motivate a patient to quit smoking or reduce alcohol intake?}

Motivation is crucial for life-style changes. The five stages of change are precontemplation (not thinking about change), contemplation (willing to consider the possibility that there is a problem), preparation, action, and maintenance. ${ }^{[31]}$ Motivation may increase through the use of a special technique called motivational interviewing (see Table 5). ${ }^{[18,32]}$

It may be efficient to ask admitted emergency patients if they see a connection between their current health status and their tobacco or alcohol use. Patients in the precontemplation stage must increase their awareness, and in the preparation stage an appropriate change strategy must be identified. ${ }^{[31]}$

Table 5. Components of motivational interviewing ${ }^{[18,32,33]}$

Components
Encouragers, including non-verbal minimal responses, such as nods and comments like: "Tell me more."
Open-ended questions to explore ambivalence.
Paraphrasing, thus the most important details of what the patient has said is reflected back. ${ }^{[33]}$
Explain to the patient that currently there is a discrepancy between the patient's actual behavior and the patient's own objectives and
values.
Praise of positive behaviors and support the person as he/she describes difficult situations, using affirmations, like "I see that you are
determined to improve your health".
Respect of the patient's autonomy, thus accept that the patient does not want to change. ${ }^{[18]}$
Periodically summarize what has been discussed.
The physician shows that he/she trusts the patient's own capacity to change. ${ }^{[18]}$


3.3.6 How to tell patients that they will not get what they want?

In Sweden, patients cannot decide themselves what treatments they will have, in case the physician disagrees. However, physicians are obliged to involve patients in treatment decisions. Patients are also not allowed to insist on being treated by a particular physician. To not accept the physician offered, corresponds to denying the treatment offered. However, in case of a life-threatening or serious disease, patients are allowed to get a second opinion from one other physician. ${ }^{[34]}$ If the patient does not consent to offered treatment, tell the patient what it implies.

\subsection{Communication with relatives}

In case of critical illness which relatives are not aware of, or if a patient's condition has deteriorated suddenly, call relatives and inform them that the patient has become seriously ill and that they should come to the hospital immediately. ${ }^{[35]}$ It is important to inform relatives about the efforts being taken to save the life of their relative. ${ }^{[35]}$ Also try to explain the possible reasons for the patient's deterioration. ${ }^{[35]} \mathrm{Un}$ fortunately, when a patient's condition is critical relatives may disregard their own needs. ${ }^{[36]}$ Therefore they should be encouraged to accommodate their need for sleep and food and be told that they can do so without needing to have a bad conscience. ${ }^{[36]}$ In case of patients with severe diseases (often patient on ventilators in intensive care units) relatives are often discouraged to stay bedside 24 hours a day. They can instead rest close by maintaining contact with the staff. This often takes place in a dedicated room for relatives, located in the hospital. Their need to be close to the patient may increase when the patient recovers and is weaned off the ventilator treatment and can then communicate better.

3.4.1 How to inform a relative of the death of a loved one? Care should be taken not to break the news of a death on the telephone unless the family members are far away. ${ }^{[35]}$ A nurse may be asked to summon the relatives to the hospital, telling them that "the patient has become seriously ill". Preferably arrange for a sit-down with the patient's relatives in a room and bring a nurse with you. Introduce yourself and say: "Unfortunately, I have very bad news". ${ }^{[18]}$ Followed by: " $\mathrm{X}$ had a heart attack (or something else leading up to the death). Despite everything the team did, we could not save his/her life."

\subsubsection{How to inform a relative of discontinuation of life sustaining treatment?}

Initially introduce yourself. Ask what information the relatives has received so far? What do they know about the current situation? Continue with: "You may have seen the deterioration of your relative?", "We have seen that your

Published by Sciedu Press relative has not improved, despite several days of intensive care, including antibiotics and ventilator treatment", and: "The possibility for your relative to survive or return to a worthy life is now minimal", "We have therefore decided to take your relative off the ventilator", "Of course, we will do everything to prevent pain and anxiety but all indicates that your relative will stop breathing and will not survive the discontinuation of the ventilator treatment", "Further ventilator treatment would only prolong the suffering and is deemed unethical".

\subsubsection{How to discuss about organ donation?}

In Sweden, organ donation, not including living donation, can only be considered in patients with cerebral catastrophes that are ventilator treated, with total brain infarction, ${ }^{[37,38]}$ due to medical intracranial catastrophes (stroke with severe brain injury), surgical intracranial catastrophes (head trauma with severe brain injury) and other reasons (intoxication, hypoxic brain injury, meningitis etc.).

Try to divide the discussion with relatives in two parts: ${ }^{[37]}$ (1) Tell the relatives about the patient's condition (that the patient has a serious brain injury and probably has a total brain infarction with a swollen brain with no blood flow). If already confirmed, inform the relatives that the patient is dead due to a total brain infarction and that the treatment now focuses to preserve organ function until the question of organ donation is clarified. (2) Discussion about organ donation. In case of ambiguity regarding the patient's wishes regarding organ donation the question has to be clarified through a discussion with the patient's relatives. It is important to focus on the patient's wishes and statements about organ donation before dying and not just ask and discuss the relatives own opinions regarding this issue. If it is still unclear what the deceased wanted, after the discussion with relatives, they should be informed that they have the right to refuse donation. In circumstances when the patient's wishes before death are uncertain, relatives should be informed that they are allowed to transfer the decision of donation to the medical staff.

\subsection{Communication with colleagues}

\subsubsection{Communication by the emergency team in an emer-} gency situation

Effective communication is crucial in successfully assessing and resuscitating critically ill patients. ${ }^{[39]}$ In closed-loop communication (CLC) the sender first transmits a message (for instance request information or ask for a procedure to be performed by a named person), ${ }^{[39]}$ that the receiver repeats back, followed by the sender confirming if the message was correctly understood or not ("Correct" or "No, I want you to..."). ${ }^{[40]}$ 


\subsubsection{How to give report about a patient to a colleague?}

When giving report about a patient to other colleagues, for instance during shift reports, we suggest the use of the communication-model SBAR (Situation, Background, Assessment, Recommendation). ${ }^{[41]}$ This model can improve the safety climate and decrease incident reports. ${ }^{[41]}$

\subsubsection{How to give and receive feedback?}

When giving feedback, be specific, and try to give the same amount of positive and negative feedback. ${ }^{[42]}$ Feedback should be actionable, thus related to something the receiver can change. ${ }^{[4]}$ Generally, also suggest a solution or outcome. ${ }^{[42]}$ Feedback should also be related to transparent performance criteria. ${ }^{[44]}$ Create an environment of safety, by giving negative feedback in privacy, and avoid making the receiver feel foolish in front of colleagues. ${ }^{[42]}$ Ideally, give feedback at the time of an event or shortly afterwards. ${ }^{[44]}$ Feedback manuals can assist in giving constructive feedback. ${ }^{[45]}$ Receivers' barriers to seek, receive, and handle feedback may stem from inaccurate self-assessments or feedback being considered as negative, ${ }^{[46]}$ and negative reactions may also prevent productive use. ${ }^{[46]}$ Time constraints may limit both the quality and the frequency of feedback. ${ }^{[43]}$

\subsubsection{Destructive communication}

Unfortunately, a survey found over $20 \%$ of physicians reported being bullied, harassed or abused from other staff in the preceding 12 months. ${ }^{[4]}$ Bullying may compromise patient safety, result in higher turnover of employees, absence due to sickness, lower productivity, costs of litigation and reputational damage. Additionally it also causes demotivation, loss of confidence, anxiety and self-doubt, and increases the risk of mental health problems. ${ }^{[47]}$ Colleagues may use master suppression techniques when perceiving someone as a threat, usually because of lack of competence or feelings of envy. ${ }^{[48]}$ Common master suppression techniques, used to control colleagues (that we discourage), are listed in Table $6^{[49]}$

Table 6. Master suppression techniques ${ }^{[49]}$

\begin{tabular}{l}
\hline Master suppression techniques \\
\hline Withholding information \\
Conveying the idea that whatever choice a person makes, it is erroneous \\
Ridiculing \\
Making invisible \\
Wrongfully making someone feel ashamed or guilty \\
\hline
\end{tabular}

Apart from the above, false rumors may be spread and victims may be punished with an abnormally high work load, limited support, and criticism for not having handled the work optimally.

Factors that promote bullying and harassment, ${ }^{[47]}$ often related to outlines decided by responsible health care politicians, are autocratic management, negative work environment, stress, work intensification, organizational changes and hierarchy, like what is seen in most hospitals.

The best ways to counteract bullying and harassment are to document it, confront the victimizer, report (and consider filing a lawsuit), build alliances, keep physically active and trying to constantly improve.

\section{Discussion}

Communication skills are crucial for physicians and complement good medical knowledge. ${ }^{[41,50]}$

An important strength with this article is the wide coverage of communication situations encountered on cardiac and intensive care units. Unfortunately, the communication styles presented in this article may sometimes be difficult to put into action, when workload or patients' needs surpass time-limits decided by local hospital administrators. Because grief and crisis reactions may take a lot of time, try to use assistance from nurses and hospital chaplains when you have to take on other tasks. Physicians with allocated administration time may have an advantage in that they can use part of it for discussions with relatives. Although, this article contains an analysis of communication in intensive care units and cardiac wards, many of the listed ideas are general, and therefore applicable to other types of wards. We think that our paper can be used in a variety of circumstances, among physicians, students, hospital administrators and healthcare leaders and be implemented in different communication courses. Healthcare leaders and medical educators should encourage physicians to use the communication techniques presented in this review to optimize the interaction with patients, relatives and colleagues.

\section{ACKNOWLEDGEMENTS}

The authors would like to thank Philip Lund, MD from Portland, OR, U.S. for linguistic advice.

\section{CONFLiCtS OF INTEREST Disclosure}

The authors declare they have no conflicts of interest. 


\section{REFERENCES}

[1] Zolnierek KB, Dimatteo MR. Physician communication and patient adherence to treatment: a meta-analysis. Med Care. 2009; 47(8): 826-834. PMid: 19584762. https://doi.org/10.1097/MLR. Ob 013 e31819a5acc

[2] Overton AR, Lowry AC. Conflict management: difficult conversations with difficult people. Clin Colon Rectal Surg. 2013; 26(4): 259-264. PMid: 24436688. https://doi.org/10.1055/s-003 3-1356728

[3] Shendurnikar N, Thakkar PA. Communication skills to ensure patient satisfaction. Indian J Pediatr. 2013; 80(11): 938-943. PMid: 23378053. https://doi.org/10.1007/s12098-012-0958-7

[4] Lang EV. A Better Patient Experience Through Better Communication. J Radiol Nurs. 2012; 31(4): 114-119. PMid: 23471099. https ://doi.org/10.1016/j.jradnu.2012.08.001

[5] Boissy A, Windover AK, Bokar D, et al. Communication Skills Training for Physicians Improves Patient Satisfaction. J Gen Intern Med. 2016; 31(7): 755-761. PMid: 26921153. https://doi.org/10.1 007/s11606-016-3597-2

[6] Janisse T. Relationship of a Physician's Well-Being to Interactions with Patients: Practices of the Highest Performing Physicians on the Art of Medicine Patient Survey. Perm J. 2008; 12(4): 70-76. PMid: 21339928. https://doi.org/10.7812/TPP/08-041

[7] Kee JWY, Khoo HS, Lim I, et al. Communication Skills in PatientDoctor Interactions: Learning from Patient Complaints. Health Professions Education. 2018; 4(2): 97-106. https ://doi .org/10.1 016/j.hpe. 2017.03 .006

[8] Wallner I, Tolf M. Humor - ett sätt att kommunicera inom vården [Humor - a way to communicate in health care]. 2014 [cited 10 November 2018]. Available from: http://lup.lub.lu.se/luur/download?func=downloadF ile\&recordOId=4378493\&f ileOId $=4378494$

[9] Hashim MJ. Patient-Centered Communication: Basic Skills. Am Fam Physician. 2017; 95(1): 29-34. PMid: 28075109.

[10] Traumatic crises. The Finnish Association for Mental Health. [cited 3 June 2018]. Available from: https : //www.mielenterveysseura .fi/en/home/mental-health/crises/traumatic-crises

[11] Roberts AR. Crisis Intervention Handbook: Assessment, Treatment, and Research. Oxford University Press. [cited 11 June 2018]. Available from: https://books.google.se/books?id=x2BKT rgRMBkC\&pg=PA229\&dq=reaction+phase+crisis\&hl=sv\&s $\mathrm{a}=\mathrm{X} \& \mathrm{ved}=0 \mathrm{ahUKEw}$ iom6 $\mathrm{f}$ Co8zbAhWCA5oKHVUsBFQQ6AEIKDAA\#v $=$ onepage \&q=reaction $\% 20$ phase $\% 20$ crisis\&f $=f$ alse

[12] Turner L. Is cultural sensitivity sometimes insensitive? Can Fam Physician. 2005; 51: 478-480, 483-475.

[13] Johnson J. Cross Cultural Communication in Medicine: Looking Within To See The Outside Better. [cited 22 nov 2018]. Available from: https://www.med.upenn.edu/gec/user_documents/J ohnson_crossculturallectureJuly112014.pdf

[14] Mast MS. On the importance of nonverbal communication in the physician-patient interaction. Patient Education and Counseling. 2007; 67(3): 315-318. PMid: 17478072. https://doi.org/10 $.1016 / j \cdot$ pec. 2007.03 .005

[15] Hall JA, Harrigan JA, Rosenthal R. Nonverbal behavior in clinicianpatient interaction. Applied \& Preventive Psychology. 1995; 4(1): 21-37. https ://doi .org/10.1016/S0962-1849(05)80049-6

[16] Griffith $\mathrm{CH}, 3$ rd, Wilson JF, Langer S, et al. House staff nonverbal communication skills and standardized patient satisfaction. J Gen Intern Med. 2003; 18(3): 170-174. PMid: 12648247. https : //doi.org/10.1046/j.1525-1497.2003.10506.x

[17] Burdick K, Kara A, Ebright P, et al. Bedside Interprofessional Rounding: The View From the Patient's Side of the Bed. J Patient Exp.
2017; 4(1): 22-27. PMid: 28725857. https://doi.org/10.117 $7 / 2374373517692910$

[18] Anderson SO, Björkegren K, Foldevi M, et al. Professionell utveckling inom läkaryrket [Professional development within the medical profession]. ISBN 978-91-47-09967-2.

[19] Kallergis G. Informing the cancer patient and family. J BUON. 2009; 14(1): 109-114. PMid: 19365879.

[20] Okamura H, Uchitomi Y, Sasako M, et al. Guidelines for telling the truth to cancer patients. Japanese National Cancer Center. Jpn J Clin Oncol. 1998; 28(1): 1-4. PMid: 9491133. https://doi.org/10 $.1093 / \mathrm{jjco} / 28.1 .1$

[21] Enayati L, Brytpunktssamtal VT. En registerstudie i palliativ vård [Information about the transition to palliative care. A registry study in palliative care]. [cited 2 June 2018]. Available from: https://gupea.ub.gu.se/bitstream/2077/45213/1/ gupea_2077_45213_1.pdf

[22] Brytpunktssamtal [Information about transition to end-of-life care]. Kils kommun. [cited 2 June 2018]. Available from: https://www.kil.se/globalassets/forvaltning/social forvalt/ledningssystem/dod_brytpunktssamtal.pdf

[23] Fritz Z, Slowther AM, Perkins GD. Resuscitation policy should focus on the patient, not the decision. BMJ. 2017; 356: j813. PMid: 28246084. https ://doi .org/10.1136/bmj · j813

[24] Ågård A, Bremer A, Sallin K, et al. Ethical controversies in the process of formulating new national guidelines on cardiopulmonary resuscitation in Sweden. Clinical Ethics. 2017; 12(4): 174-179. https://doi.org/10.1177/1477750917724331

[25] Ågård A, Engström I. Nya etiska riktlinjer för hjärt-lungräddning väl förankrade i svensk vård [New ethical guidelines for cardiopulmonary resuscitation well-anchored in Swedish healthcare]. Läkartidningen 2014; 111: CMD9. [cited 2 June 2018]. Available from: http: //www.lakartidningen.se/Klinik-och-vetenskap/Eti k-och-lakarroll/2014/01/Nya-etiska-riktlinjer-for -hjartlungraddning-val-forankrade-i-svensk-vard/

[26] Lofmark R, Nilstun T. Not if, but how: one way to talk with patients about forgoing life support. Postgrad Med J. 2000; 76(891): 26-28 PMid: 10622776. https://doi.org/10.1136/pmj.76.891.26

[27] Murphy DJ, Burrows D, Santilli S, et al. The influence of the probability of survival on patients' preferences regarding cardiopulmonary resuscitation. N Engl J Med. 1994; 330(8): 545-549. PMid: 8302322 https://doi.org/10.1056/NEJM199402243300807

[28] Adams DH, Snedden DP. How Misconceptions Among Elderly Patients Regarding Survival Outcomes of Inpatient Cardiopulmonary Resuscitation Affect Do-Not-Resuscitate Orders. The Journal of the American Osteopathic Association. 2006; 106(7): 402-404. PMid: 16912338.

[29] Girotra S, Nallamothu BK, Spertus JA, et al. Trends in Survival after In-Hospital Cardiac Arrest. New England Journal of Medicine. 2012; 367(20): 1912-1920. PMid: 23150959. https://doi.org/10.1 056/NEJMoa1109148

[30] Etheridge Z, Gatland E. When and how to discuss "do not resuscitate" decisions with patients. BMJ. 2015; 350: h2640. PMid: 25994629. https://doi.org/10.1136/bmj.h2640

[31] Substance Abuse and Mental Health Services Administration. Center for Substance Abuse Treatment. Enhancing Motivation For Change in Substance Abuse Treatment. [cited 2 June 2018]. Available from: https://www.ncbi.nlm.nih.gov/books/NBK64967/pd f/Bookshelf_NBK64967.pdf

[32] Motivational Interviewing Steps and Core skills. [cited 2 June 2018] Available from: https://www.ihs.gov/california/tasks/s ites/default/assets/File/BP2015-4_TeachingSBIRTFa cultyGuideSession3Part2.pdf 
[33] Encouragers, Paraphrasing and Summarising. Counselling Connection. [cited 2 June 2018]. Available from: http://www . counsellingconnection.com/index.php/20 09/07/21/encouragers-paraphrasing-and-summarising/

[34] Ny medicinsk bedömning, second opinion [New medical assessment, second opinion]. 1177 Vårdguiden. [cited 3 June 2018]. Available from: https://www.1177.se/Regler-och-rattigheter/Sec ond-opinion-en-andra-lakarbedomning/

[35] Naik SB. Death in the hospital: Breaking the bad news to the bereaved family. Indian J Crit Care Med. 2013; 17(3): 178-181. PMid: 24082616. https://doi.org/10.4103/0972-5229.117067

[36] Gulbrandsen T, Stubberud DG. Intensivvård. Avancerad omvårdnad och behandling [Intensive care. Advanced care and treatment]. ISBN: 9789144037714. 2009.

[37] Organdonation - Lokal Handlingsplan [Organ donation - Local action plan]. Region Örebro län. Revised 22 June 2015.

[38] Olausson M. Organ Transplantation in Sweden. Transplantation. 2016; 100(2): 251-255. PMid: 26813406. https://doi.org/10 $.1097 /$ TP .0000000000001109

[39] Major Trauma Guidelines \& Education. Victorian Department of Health. [cited 3 June 2018]. Available from: https://trauma.reach.vic.gov.au/guidelines/tea mwork-and-communication/effective-communication

[40] Backlund EL. Kommunikationsmodellers påverkan på kommunikationen och patientsäkerheten i akuta situationer [Communication models' influences on communication and patient safety in emergency situations]. [cited 3 June 2018]. Available from: http://www.theseus.fi/bitstream/handle/10024/85387/ Backlund_Eva-Lotta. pdf ; jsessionid $=4$ A4692533740EC6C 197C9F5FAE27BF99? sequence $=1$

[41] Bjurman C, Juhlin T, Holzmann MJ. Suggested improvements of the general cardiology ward round - An opinion paper. JHA. 2018; 7(1): 18-26. https://doi.org/10.5430/jha.v7n1p18
[42] 5 Steps for Giving Productive Feedback. Entrepreneur Europe. [cited 3 June 2018]. Available from: https://www. entrepreneur.com /article/219437

[43] Kornegay JG, Kraut A, Manthey D, et al. Feedback in Medical Education: A Critical Appraisal. AEM Education and Training. 2017; 1(2): 98-109. PMid: 30051017. https://doi .org/10.1002/ae t2. 10024

[44] Cantillon P, Sargeant J. Giving feedback in clinical settings. BMJ. 2008; 337. https ://doi .org/10.1136/bmj .a1961

[45] Bjurman C. Improved clinical training of internal medicine students in hospital wards. JHA. 2018; 7(1): 43-52. https ://doi .org/10 $.5430 / j$ ha.v7n1p43

[46] Algiraigri AH. Ten tips for receiving feedback effectively in clinical practice. Medical Education Online. 2014; 19(1): 25141. PMid: 25079664. https://doi.org/10.3402/meo.v19.25141

[47] Workplace bullying and harassment of doctors. A review of recent research. British Medical Association. [cited 1 June 2018]. Available from: https://www.bma.org.uk/-/media/files/pdfs/col lective\%20voice/policy\%20research/education $\% 20$ and $\%$ 20 training/bullying\% 20 and $\% 20$ harassment $\% 20$ research $\%$ 20 review\%20v7\%20web.pdf?la=en

[48] Åslund A. Retorikern: Så stoppar du härskartekniker på jobbet [The rhetorician: How to stop master suppression techniques at work]. Metro jobb. [cited 3 June 2018]. Available from: https: //www.metrojobb.se/artikel/8117-retorikern-s\%C3\%A5 - stoppar-du-h\%C3\%A4rskartekniker-p\%C3\%A5-jobbet

[49] Training Guide to Master Suppression Techniques and Counter Strategies. [cited 3 June 2018]. Available from: http: //netbox-production.s3.eu-central-1.amazonaws.c om/resources/1c6a3e3129aa4c859ac2d52bbe44a2e8.pdf

[50] Bjurman C, Mangafic S, Holzmann MJ. Improvements of the working conditions for physicians and patient safety in emergency departments. JHA. 2018; 7(4): 17-26. https://doi .org/10.5430/jha. v7n4p17 